\title{
EFFECT OF NEONATAL OESTROGEN AND hCG TREATMENT ON THE GENITAL ORGANS OF ADULT FEMALE RATS
}

\author{
Zora Nikolić, Zdenka BlagoJeVIĆ, Verica MRVIĆ and I. IVANOV \\ Faculty of Veterinary Medicine, Bulevar JNA 18, 11000 Beograd, Yugoslavia
}

(Received October 25, 1997; accepted February 4, 1998)

\begin{abstract}
The ovaries and the uterine as well as vaginal mucous membranes of 80-, 180 - and 365-day-old intact female rats and females neonatally treated with a single dose of oestrogen and repeated doses of human chorionic gonadotropin (hCG) were studied. Numerous follicles, interstitial cells and corpora lutea (CL) were present on the ovary of intact females from 80 up to 365 days of age. The number of primary and secondary follicles decreased in the intact female rats between Day 180 and Day 365 of life. On the ovaries of 180- and 365-day-old female rats neonatally treated with oestrogen, interstitial glandular cells and cystic follicles predominated. No CL were present on these ovaries. The height of epithelial cells of the uterine and vaginal mucous membranes increased in intact female rats from 80 to 365 days of age, whereas in oestrogen-treated females the height of epithelium decreased. From 80 up to 365 days of age, the height of epithelial cells of uterine and vaginal mucous membranes of rats neonatally treated with repeated doses of hCG was similar to that in the corresponding control animals.
\end{abstract}

Key words: Rat, ovary, uterus, vagina, oestrogen, hCG

The progressive decline of regular oestrous cycles and ovulatory functions with advancing age in female rats has been well documented in previous studies (Pantic and Lovren, 1981; Ennis and Davies, 1982; Nass et al., 1984). In female rats and mice, neonatal oestrogen treatment induces changes in the reproductive tract that may persist throughout the animal's life (Pantic, 1981). These changes include a persistent rather than cyclic oestrus. During persistent oestrus, circulating oestradiol is present from many large ovarian follicles, but the luteinizing hormone surge mechanism is inhibited and ovulation does not occur (Leung, 1978; Pantic and Lovren, 1981).

Studies on abnormalities of the reproductive tract indicate that oestrogens have inhibitory effects on ovarian steroidogenesis (Groen-Clevant, 1981; Wada et al., 1984). The uterus and vagina are also dependent on the effect of hormones administered to neonates (Ennis and Davies, 1982; Keys and King, 1989).

In this paper, attention is focused on the ovarian follicles and interstitial tissue and on the properties of uterus and vagina in adult rats neonatally treated with oestrogen and human chorionic gonadotropin (hCG). 


\section{Materials and methods}

Sixty female Wistar rats divided into three groups were used. The first group, of 18 females, received $1 \mathrm{mg}$ oestradiol dipropionate on the third day of life, and the animals were killed painlessly on Days 80,180 or 365 of life. To the second group of twelve females, 50 IU hCG was injected on the third and sixth day of life, and these animals were sacrificed at the age of 38 and 90 days. The third group of 30 rats included intact females. Ovaries, uteri and vaginae were isolated, fixed in Bouin's solution, stained with haematoxylin-eosin, and examined by light microscopy. Statistical analysis was done by Student's $t$-test.

\section{Results and discussion}

The ovarian mass of control rats decreased from $144.6 \mathrm{mg}$ on Day 80 to $100.1 \mathrm{mg}$ on Day 365. In animals neonatally treated with oestrogen, ovarian mass on Days 80 and 180 was significantly lower than in the corresponding controls (by $45 \%$ and $54.1 \%$, respectively).

Several primary, secondary and Graafian follicles and corpora lutea (CL) were present on the ovaries of 80-day-old female rats (Fig. 1a). The interstitial glandular cells were grouped in islets of $110 \times 320 \mu \mathrm{m}$ in diameter. From 180 to 365 days of age, CL and interstitial glandular cells were present on the ovary of intact female rats. On these ovaries primary follicles were rare and scattered between interstitial glandular cells. There were 13.6 secondary follicles and 12 CL per section. At 80 days of age, the number of growing antral follicles was reduced on the ovary female rats neonatally treated with oestrogen. In the largest antral follicles $254 \times 232 \mu \mathrm{m}$ in diameter, degenerative changes were expressed in the granulosa and theca cells. The thickness of theca folliculi of the antral follicles was half that found in the corresponding controls. The preovulatory follicles were cystoid or even cystic (Fig. 1b). The interstitial glands occupied most of the ovarian cortex. Their size and shape were irregular. In rats of 180 and 365 days of age, neonatally treated with oestrogen, the number of secondary follicles was significantly decreased. On the ovary of 180-dayold females some of largest secondary follicles had more than 22 layers without a clear tendency for antrum formation (Fig. 2a). Pituitary gonadotropin has an important role in the maturation of secondary follicles in intact female rats (Arakawa et al., 1989). Thus, follicular development was retarded in mice treated with pituitary antigonadotropin for seven days at birth (Lunenfeld, 1969). Oestrogen administered neonatally to rats and mice has an inhibitory effect on ovarian responsiveness to gonadotropins (Leung et al., 1978; Pantic, 1981; Pantic and Lovren, 1981). 


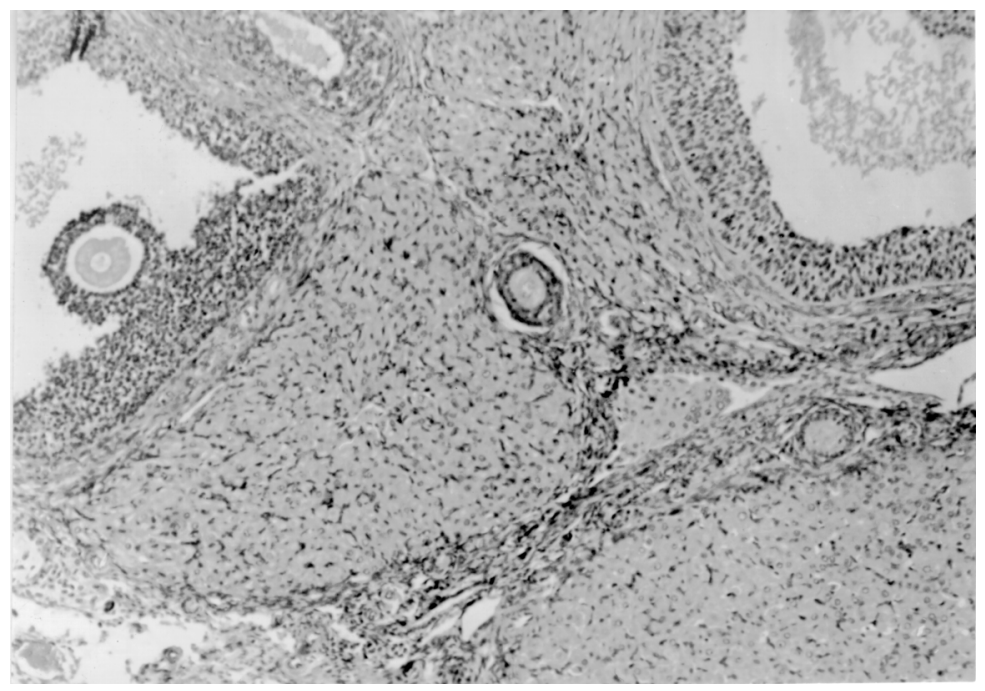

Fig. 1a. Corpora lutea and maturating follicles in the ovaries of 80 -day-old female rats

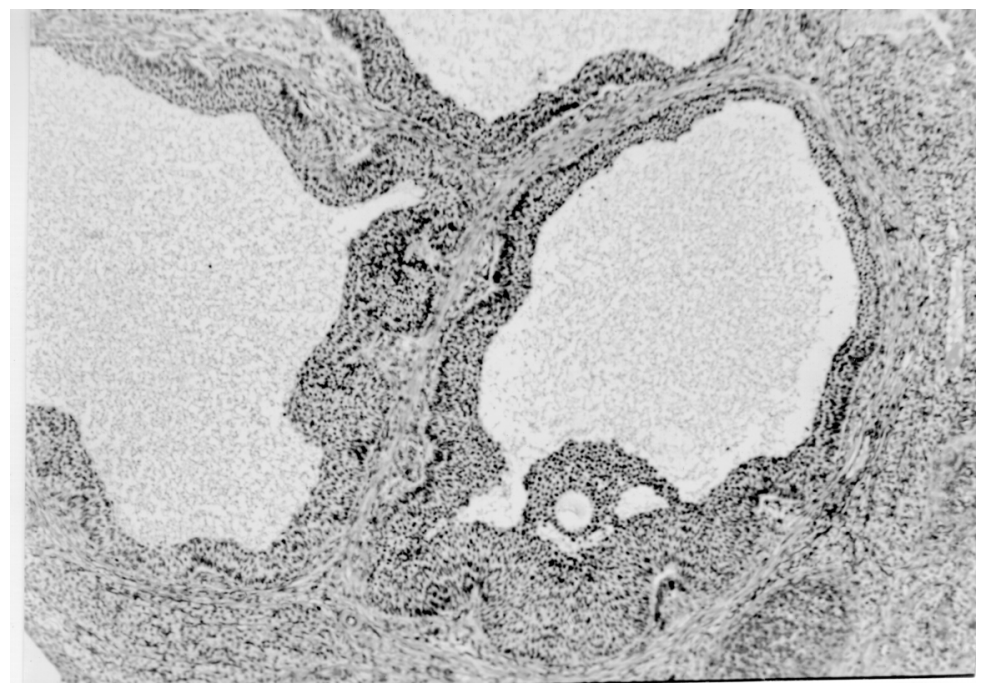

Fig. 1 b. Cystoid preovulatory follicles in the ovary of 80 -day-old female rats neonatally treated with oestrogen

The ovary of 365-day-old females neonatally treated with oestrogen contained predominantly interstitial glands and cystic follicles (Fig. $2 b$ ). Several papers demonstrated that the alteration of granulosa cells and thecal layer resulted in transformation of the preovulatory follicles into ovarian cysts and in increasing of the interstitial 
glands (Guraya, 1978; Pantic and Lovren, 1981; Adams, 1986). The interstitial glands were grouped in lobate form and distributed from the tunica albuginea towards the medulla. $\mathrm{CL}$ were not formed in rats neonatally treated with oestrogen.

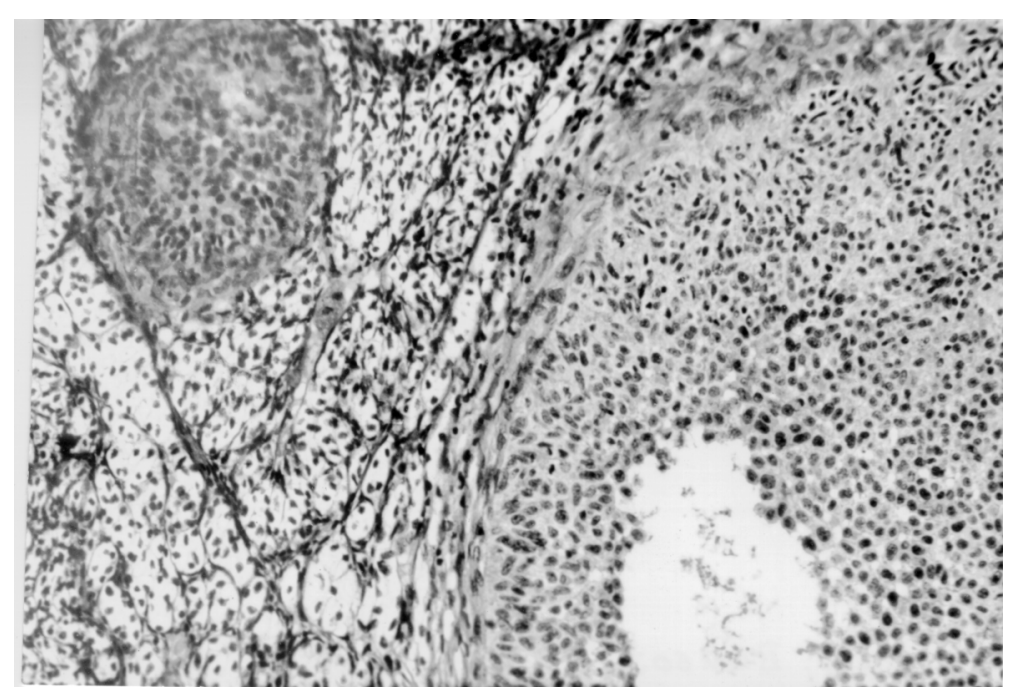

Fig. 2a. Secondary follicles and interstitial glands in the ovary of 180-day-old female rats neonatally treated with oestrogen

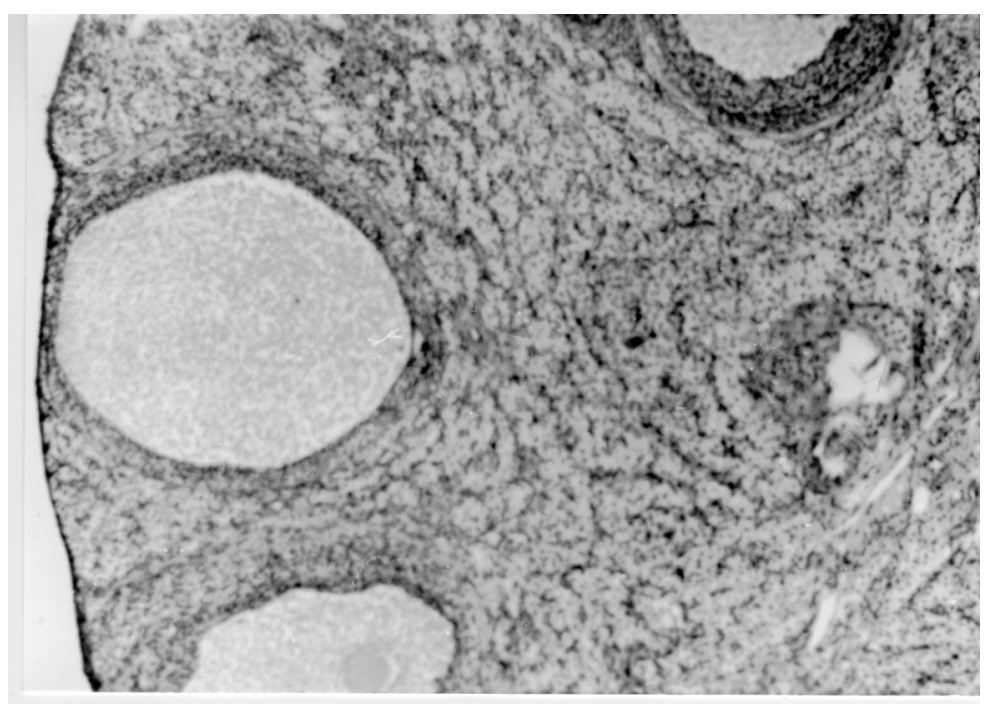

Fig. 2b. Interstitial glands and cystic follicles in the ovary of 365-day-old females neonatally treated with oestrogen 
By 80 days of age all layers of the uterus had developed. The height of epithelial cells of the uterine mucous membrane averaged $19.00 \mu \mathrm{m}$. The epithelial cells were highly prismatic. The uterine mucous membranes of the 80and 365-day-old rats grew in thickness to 22.4 and $24.9 \mu \mathrm{m}$, respectively. In 80day-old females neonatally treated with oestrogen, the uterine epithelium was lower prismatic and totalled $21.7 \mu \mathrm{m}$ in height; however, it was 1.1 times higher than that of the corresponding controls. The uterine glands were evident in the mucous membranes. The uterine epithelium of 180- and 365-day-old females neonatally treated with oestrogen was lower prismatic and totalled 12.5 and $10.1 \mu \mathrm{m}$ in height. It was 1.8 and 2.4 times lower than that of the controls.

Several references in the literature indicated that uterine development is dependent on the dose of the oestradiol. Thus, a physiological dose of oestrogen in women resulted in proliferation and hyperaemia of the uterine stroma and glands (Hellweg, 1980). Long-term oestrogen treatment of female rats resulted in uterine atrophy (Egger and Kindermann, 1980). The circular layer of the myometrium was reduced and disorganised in these animals (Brody and Cunha, 1989).

The thickness of the vaginal mucous membrane on days 80,180 and 365 was increased from $50.3 \mu \mathrm{m}$ to $61.2 \mu \mathrm{m}$. The epithelium was 1.1 times higher than in the corresponding controls. However, at 180 and 365 days of age the vaginal epithelium of oestrogen-treated females was 1.5 times lower than that of the controls. In the same females a mucoid degeneration of the vaginal epithelium was evident (Fig. 3a).

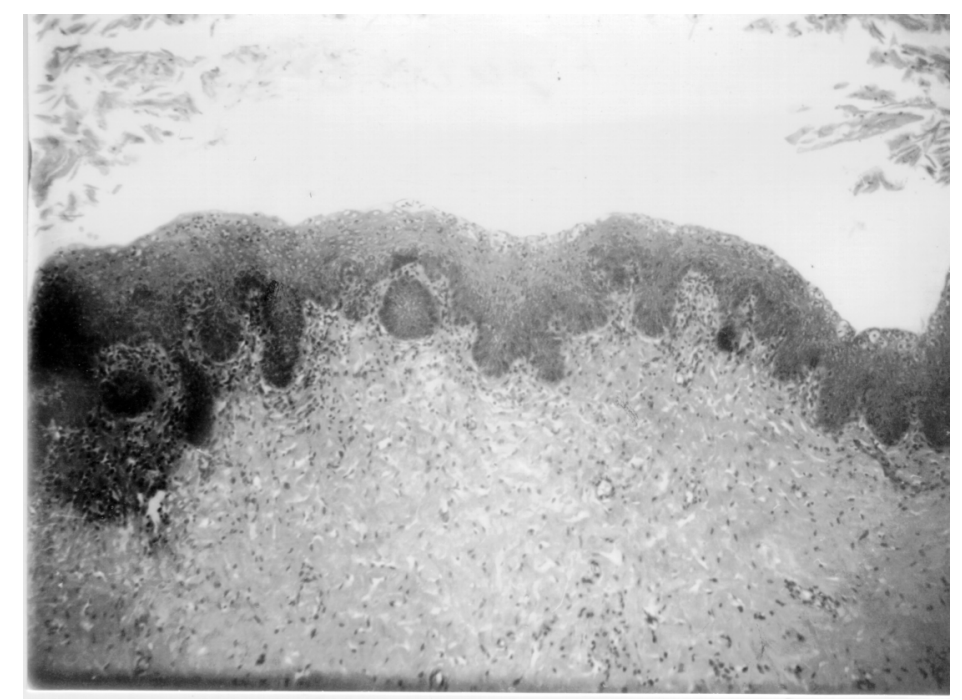

Fig. 3a. Mucoid degeneration in the vaginal epithelium of 365-day-old female rats treated neonatally with oestrogen 
A single injection of oestradiol valerate causes a rapid onset of persistent vaginal cornification in adult cycling female rats (Brawer et al., 1978) and mice (Takasugi, 1979; Forsberg and Kalland, 1981). In rats treated neonatally with diethylstilboestrol (DES), Ennis and Davies (1982) reported squamous metaplasia of the uterine epithelium. Intrauterine DES exposure resulted in non-neoplastic alteration of the uterine cervix and vagina (Robboy et al., 1977) or adenocarcinoma of these organs (Herbst et al., 1979).

The difference between hCG-treated and control female rats in the height of uterine and vaginal epithelium was not significant. The height of uterine epithelium totalled $163.0 \mu \mathrm{m}$ and that of vaginal epithelium $62.0 \mu \mathrm{m}$ in the rats neonatally treated with repeated doses of hCG. hCG is very similar to LH but different from the latter mainly in the $\beta$-subunit (Hartree et al., 1971; Carlsen et al., 1973). Binding of hCG depends on the values of endogenous LH. The highest hCG binding was observed in the ovaries of adult female rats in dioestrus, when the concentration of LH was low (Siebers et al., 1977).

\section{References}

Adams, W. C. (1986): Hormonal changes in the early development of ovarian cysts in the rat. Biol. Reprod. 35, 542-548.

Arakawa, S., Iyo, M., Ohkawa, R., Kambegawa, A., Okinaga, S. and Arai, K. (1989): Steroid hormone receptors in the uterus and ovary of immature rats treated with gonadotropins. Endocrinol. Japan 36, 219-228.

Brawer, J. A., Naftolin, F., Martin, J. and Sonnenhein, C. (1978): Effects of a single injection of estradiol valerate on the hypothalamic arcuate nucleus and on reproductive function in female rats. Endocrinology 103, 501-512.

Brody, J. and Cunha, G. (1989): Histologic, morphometric and immunocytochemical analysis of myometrial development in rats and mouse: Effects of DES on development. Am. J. Anat. 186, 21-42.

Carlsen, R., Bahl, P. and Swaminathan, N. (1973): Human chorionic gonadotropin. J. Biol. Chem. 248, 681-690.

Egger, H. and Kindermann, N. (1980): Effects of high estrogen doses on the endometrium. In: Dallenbach-Hellweg, G. (ed.) Functional Morphologic Changes in Female Sex Organs induced by Exogenous Hormones. Springer Verlag, Berlin-Heidelberg-New York.

Ennis, B. and Davies, J. (1982): Reproductive tract abnormalities in rats treated neonatally with DES. Am. J. Anat. 164, 145-154.

Forsberg, J. and Kalland, T. (1981): Neonatal estrogen treatment and epithelial abnormalities in the cervicovaginal epithelium of adult mice. Cancer Res. 41, 721-734.

Groen-Clevant, A. C. (1981): An autoradiographic study of follicle growth in the ovaries of cyclic rats. Acta Endocrinol. 96, 377-381.

Guraya, S. (1978): Recent advances in the morphology, histochemistry and physiology of interstitial gland cells of mammalian ovary. Int. Rev. Cytol. 55, 173-239.

Hartree, A., Thomas, M., Braikevitch, M., Bell, E. and Christied, W. (1971): Preparation and properties of subunits of human luteinizing hormone. J. Endocrinol. 51, 169-180. 
Hellweg, G. (1980): Morphological changes induced in human uterus and fallopian tube by exogenous estrogens. Springer-Verlag, Berlin-Heidelberg-New York.

Herbst, A., Scully, R. and Robboy, S. (1979): Prenatal exposure and human genital tract abnormalities. Natl. Cancer Inst. Monogr. 51, 25-35.

Keys, J. L. and King, G. J. (1989): Structural changes in the luminal epithelium of the porcine uterus between days 10 and 19 of the estrous cycle. Am. J. Anat. 185, 42-57.

Leung, P. (1978): An interovarian inhibitory action of estrogen and androgen production in vivo. Biol. Reprod. 19, 641-647.

Lunenfeld, B. and Eshklab, A. (1968): The role of gonad stimulatory hormone on the development of the infantile ovary. In: Rosember, E. (ed.) Gonadotropins. Geron-x, Los Altos, pp. 197-204.

Nass, T., Matt, D., Judd, H. and Lu, J. (1984): Prepubertal treatment with estrogen or progesterone precipitates the loss of regular estrous cyclity and normal gonadotropin secretion in adult female rats. Biol. Reprod. 31, 723-731.

Pantic, V. (1981): Sensitivity of pituitary gonadotropic cells and gonads to hormones in reproductive processes and contraception. Bioch. Endocrinol. Plenum Press, New York-San Francisco-London, pp. 47-89.

Pantic, V. and Lovren, M. (1981): Ovaries of adult rats neonatally treated with a single dose of estrogen. Acta Vet. Beograd 31, 61-72.

Robboy, S. J., Scully, R. E., Welch, W. and Herbst, A. (1977): Intrauterine DES exposure and its consequences. Arch. Pathol. Lab. Med. 101, 1-5.

Siebers, J., Peters, F. and Engel, W. (1977): Ovarian hCG-binding capacity during the estrous cycle of the rat. Acta Endocrinol. 85, 850-853.

Takasugi, N. (1979): Development of permanently proliferated and cornified vaginal epithelium in mouse treated neonatally with steroid hormone and the implication for tumorogenesis. Natl. Cancer Inst. Monogr. 51, 57-66.

Wada, Y., Yajima, A., Suzuki, M. and Greenwald, G. (1984): In vitro effects of estradiol, testosterone and progesterone on luteal steroidogenesis in the pregnant rats. Endocrinol. Japan 31, 207-215. 